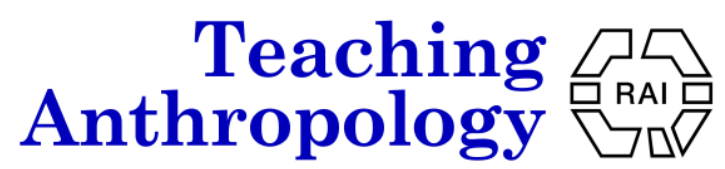

2021, Vol. 10, No.3, pp. 90-96.

Developing Teaching: Reports and Reflections

\section{Digital Storytelling as Pedagogy in Linguistic Anthropology}

\author{
Jessica Sujata Chandras ${ }^{1}$ \\ ${ }^{1}$ Department of Anthropology, Wake Forest University
}

\begin{abstract}
:
This article explores teaching linguistic anthropology through digital storytelling as a pedagogical foundation. In a course titled Language, Power, and Social Identity, offered remotely in the fall of 2020 at Kenyon College in Ohio, storytelling practices provided a way to explore connections between language and identities among a diverse group of twelve students. Using storytelling throughout the semester in multiple ways, activities and assignments culminated in a final class project of individual digital storytelling videos. Reflection on this course suggest integrating digital storytelling as pedagogy can generate greater understanding of identity formation through creative and inclusive learning practices.
\end{abstract}

Keywords: Storytelling, Digital Storytelling, Pedagogy, Linguistic Anthropology, Identity

"Constant experimentation is the essence of successful digital storytelling."

\section{Introduction}

(Joe Lambert, 2017, p.26)

Digital Storytelling, drawn from storytelling pedagogy and media studies, is a heartfelt video exploration of a broad range of topics told through compelling audio-visual narratives made using accessible digital media software. As a genre, digital stories are simple and relatively short multimedia presentations of recorded audio, music, and images compiled into 5-7 minute video recordings "using predominantly still images combined with recorded voice-over, and often includ[e] music and/or other sounds" in the background (Dunford \& Jenkins, 2017:3). The process of implementing digital storytelling as pedagogy opens avenues for teaching anthropological concepts and has the potential to generate class involvement in online learning situations. In this article, I outline my use of digital storytelling in an undergraduate special topics course in the fall semester of the 2020-2021 academic year, where my central goal was to have students connect concepts around privilege and structures of oppression to experiences in their own lives or what they have witnessed in their communities through the lens of language imbued with power. In past courses, I saw that technical linguistic concepts, theoretical material, and academic texts remained disconnected from the personal lives of many students or were reflected on solely at the end of the course in final essay assignments. To address this I introduced digital storytelling as part of the seminar course in linguistic anthropology, titled Language, Power, and Social Identities, to integrate scaffolded ways of learning that used narrative exposition unique to digital storytelling to connect weekly themes to student experiences. This also had the benefit of fostering collaborative learning despite all students accessing the class virtually.

Emerging in the mid-1990's as an arts-based multimedia presentation format using a narrative structure, digital storytelling can be used to document, explore, and communicate a wide array of lived experiences (Dunford \& Jenkins, 2017; Lambert, 2017; Lambert \& Hessler, 2018). As my linguistic anthropology course aimed to examine how individuals create and perform their social identities through and in response to language, implementing an oral and narrative method of practice and analysis assisted in exploring how the variables of identity categories tied to language intersect, clash, and can be resolved. The digital storytelling component in this course was a final video project completed in stages, which asked students to develop a digital video story about an aspect of their own identities in response to a course topic relating to language, power, and identity construction. Students presented their final digital storytelling projects in videos ranging from 3 to 7 minutes for each other at the end of the semester. The video explorations of personal stories that students crafted related to aspects of their identities and popular culture by building upon a course topic, question, or sociolinguistic concept. Students also incorporated sources from class materials and independently sourced outside scholarship as citational evidence. 
In this article, I explain the course goals, pedagogical plan, and learning outcomes after a brief review of digital storytelling foundations, methods, and pedagogy. My goal of incorporating digital storytelling as both a method and genre into the course was to provide a multi-sensory, interdisciplinary, inclusive, creative, and personalized platform for students to process and synthesize course material in relation to their own intimate entanglements with course topics and each other while studying remotely.

\section{Digital Storytelling as Pedagogy}

Storytelling "involves a particular language and set of relationships [as] a body of knowledge and abilities that are activated only when it is happening," and digital storytelling pedagogy provides an accessible method for making conceptual connections through narrative exposition (Kuyvenhoven, 2009:4). Digital storytelling provides a vehicle not only for students to learn about contentious and sensitive topics (Aguilera et al., 2020; Benick, 2012; Rolon-Dow, 2011; Stewart \& Gachago, 2016; Stewart \& Ivala, 2017), but also functions as pedagogy, or a method and practice for teaching by facilitating groups of students to develop individualized stories that draw connections between course concepts and their own lives (Alexander, 2011; Benmayor, 2008, Jamissen et al., 2017; Lambert, 2017). Digital storytelling pedagogies extend the narrative and reflective approach of storytelling pedagogy to introduce guided critical reflection and video making in conjunction with media literacy using free or inexpensive intuitive online software programs such as WeVideo (Hessler \& Lambert, 2017; Tyner, 1998). As a method, it is "a creative process whereby people with little or no experience of computers, gain the skills needed to tell a personal story" in video format (Dunford \& Jenkins, 2017, p.3). In short, digital stories are brief, self-representational multimedia presentations.

A key element of the digital storytelling pedagogy I employed was to ensure the final video products emerged from a collaborative, participatory dialogue process where students created and reviewed scripts, received feedback from each other on images and music, and finally presented personalized digital video stories to the entire class (Dunford \& Jenkins, 2017). Just as storytelling is a form of dialogue between a storyteller and an audience, scaffolded discussion-based activities and assignments provided collaborative development of a narrative between the individual student and the class, which shaped their eventual video projects and allowed students to grasp how others see and respond to their submissions, facilitating interactive space within a remote learning context.

Digital storytelling facilitators and scholars, Joe Lambert and Brooke Hessler from the organization, StoryCenter (formally called the Center for Digital Storytelling) have written about the transformational process of creating digital stories as a pedagogical foundation in educational spaces. Throughout their scholarship, they present digital storytelling as a process cannot be divorced from the product (Hessler \& Lambert, 2017; Lambert, 2017). Hessler and Lambert (2017) express this point in their conception of story work:

We start with encouraging the storytellers' sense of fundamental authority on their own personal experience. Even as they may be framing a subject, or addressing a broader issue, their starting point is how they understand their own awareness of the way the story works, where it currently works upon them, and where with group reflection and individual feedback, they would like to transform those understandings. (p.32).

By positioning the process of storytelling as emerging from students as authors, Hessler and Lambert (2017) extend to digital storytelling Myer and Land's (2003) "Threshold Concepts", to describe those transformative pedagogical practices that create significant shifts in student understanding. When applied to digital storytelling, Hessler and Lambert specify that the transformative processes of digital story making, in part, derives from narratives informed by intimacy and safety produced within a collaborative process of story-making as a means of communication and critical literacy (2017, p.26-27). This understanding of digital storytelling pedagogy guided my use of digital storytelling as a practice-based method for teaching linguistic anthropology in the Language, Power, and Social Identities seminar. It provided a means to shift individual perspectives on deeply personal, intimate, and integrated topics of identity and language to a collective experience of dialogue that resonated with the course material (see Kaare, 2012 for a similar point).

In anthropology, visual ethnography often brings together storytelling through digital media (Alexandra, 2008; Pink, 2007; Nuñez-Janes et al., 2017) and narrative learning (Hakanurmi, 2017). Thornburg et al. (2017) similarly focus on the collaborative and communicative process of meaning-making, when they describe ethnography as storytelling. Digital storytelling then, can be considered a form of visual auto-ethnography that can bring to light perspectives on identity creation (Benick, 2012; Hakanurmi, 2017; Rolon-Dow, 2011), migration (Alexandra, 
2008; Stewart \& Gachago, 2016), and critical perspectives of belonging in education (Aguilera et al., 2020; Kaare, 2012; Stewart \& Ivala, 2017). Within anthropology courses, digital storytelling can be used to teach participatory media education, media literacy, and critical perspectives of identity and community, through reflexive, reflective, oral practices (Dunford \& Jenkins, 2017; Lambert, 2017; Tyner, 1998). Expanding the use of digital storytelling in teaching also creates, as a by-product, opportunities to deepen our understanding of visual ethnography as a method.

\section{Applying Digital Storytelling in the Course}

Language, Power, and Social Identities (Anth391) was a special topics course offered for the first time in the fall semester of 2020 to upper-division students studying remotely at Kenyon College, a small liberal arts school in the village of Gambier in Ohio. It was not limited to anthropology majors or minors though it satisfied elective credits in the department and diversification requirements for students majoring in other disciplines. The resulting class composition included twelve students across sophomore, junior, and senior years and numerous majors. This seminar was offered in the midst of major changes to course delivery due to Covid19 along with the weight of beginning a semester, remotely (online), in the shadow of protests against police brutality and calling for equal treatment of Black lives in the summer of 2020. It was imperative to how I conceived the class that students enter the virtual classroom in our synchronous sessions not as an escape from their realities but as a space for honing and practicing skills to name, confront, and process social injustices outside of our class. As such, integrating pedagogies of digital storytelling into the curriculum proved to be a successful method for inclusively connecting linguistic anthropological material to the lives of a diverse group of remote learners and for creating a safe space to explore intimate and sensitive topics.

I designed the course to examine how individuals create and perform their social identities through and in response to language, with special attention to prejudice, standardization, and privilege. In the first two weeks, we focused on foundational concepts about identity construction and linguistics, specifically semiotics. Then, weekly units of material progressed through closer examination of social variables such as race, ethnicity, class, gender, sexuality, disability, geography, power, ideology, etc. Throughout the fifteen weeks of instruction populated with scholarly texts, film, podcasts, and popular and news media, students explored how these variables of identity intersect and are contested and resisted. Students were asked to submit a weekly reading reflection synthesizing the material with opportunities to submit the weekly material in writing, by audio or video recording, or to me in a short live presentation at a specified appointment time before class. I made sure to clearly articulate that I would evaluate each submission format and provide feedback in writing about the student's synthesis of all weekly material, rather than a summary of reading material, and the inclusion of two discussion questions. While about two thirds of students submitted their reflections in writing each week, many chose to orally present material to me directly. One student justified her choice to present directly to me in an appointment each week by explaining how talking about the readings with me honed her verbal processing skills and better prepared her to complete the storytelling component of the final project. I found that students' oral presentations of the weekly reading reflections often contributed to more thorough synthesis than written reflection papers because students tended to summarize readings at greater length in writing than when verbally processing their responses to readings and other weekly material. Overall, the flexible submission formatting encouraged students to process material in ways that suited their learning styles and time constraints each week.

In addition to the weekly reflection assignments, students also had the chance to speak with two guest lecturers who I invited into our class to speak about storytelling. One, conceptual artist Luis Camnitzer, explained his process for storytelling through materials in his art. The second guest speaker, anthropologist Dr. Sarah Wagner, winner of the 2020 Victor Turner Prize for Ethnographic Writing, shared with students how she drew connections between evocative storytelling and ethnographic research and writing. The course also featured two larger assignments, in addition to weekly reflection assignments, central to my goal of facilitating students in connecting course concepts to their own lives. As a midterm evaluation, students wrote essays explaining the connection between a course concept and a contemporary news media article. The second main assignment in the course was a multi-step digital storytelling video project, which I explain in detail below.

\section{Digital Storytelling Project Process}

I initiated the digital storytelling project through scaffolded assignments beginning in week four of the semester. In that week, I asked students to first listen to and reflect on stories told about aspects of identities. After listening through a story of their choice from a selection of options I provided, students drew upon the 
storytelling examples and explained in a short writing assignment how identity was conceived of by the story author and what transformation they underwent in the story. Examples of spoken stories were drawn from the podcast and storytelling initiatives, The Moth and StoryCenter. Students were then introduced to a digital story with the help of the Center for Innovative Pedagogy (CIP) at Kenyon College who facilitate digital storytelling workshops with faculty and students. In a session in the eleventh week of the semester with CIP facilitators, students viewed examples of digital stories, including my own from a summer workshop, to learn how to craft a five minute script of a digital story (see www.storycenter.org for more details). However, before writing a script, I asked students to write a brief topic proposal of 250 words, with an annotated bibliography, using one source from our assigned readings in the course and one related outside source to frame the topic of their scripts. In this assignment students began to conceptualize their digital stories by first describing a topic they were interested in and evaluating it in its relation to weekly topics in the course.

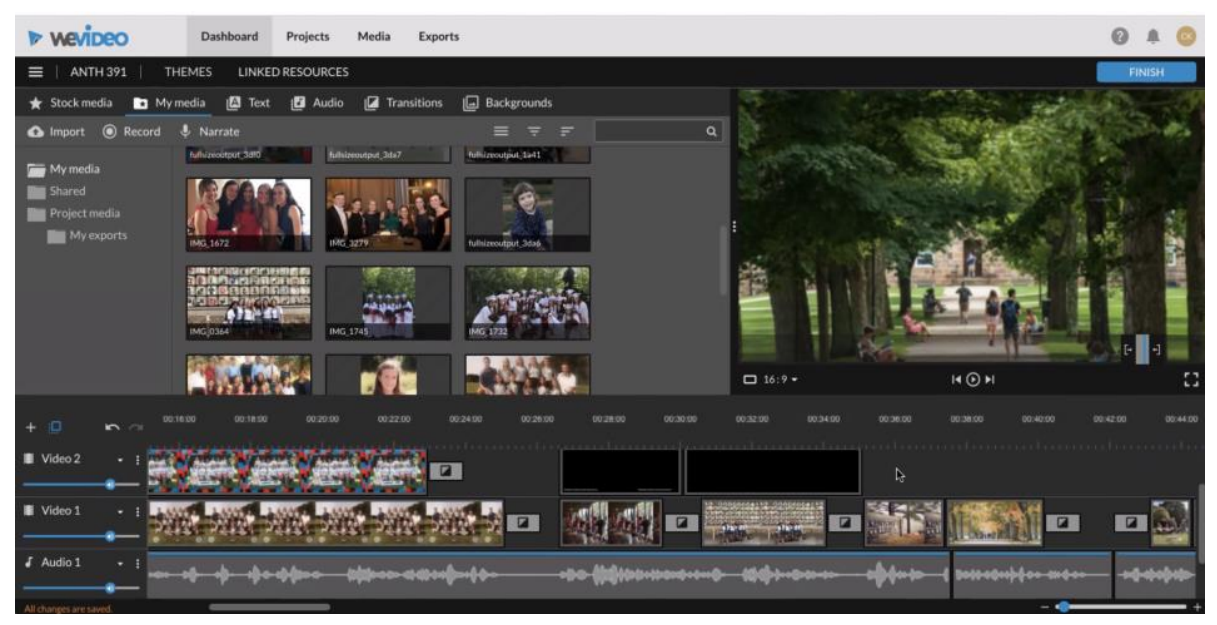

Image 1: A student s work in WeVideo, shared in this article with their permission.

After another session with CIP facilitators in the twelfth week of the semester, students learned how to use the multimedia editing software, WeVideo, and students submitted a story script of roughly 500 words for a peer review activity. In the peer-review activity in the fourteenth week of the class, I divided students into groups of three to read and comment on each other's story scripts. In small groups in break out rooms on Zoom, students evaluated their peer's stories for the clarity of their ideas in writing and to make sure the narrative arcs of their stories were clearly communicating a concept from the class in connection to their identities. Based on feedback from their peers, students recorded themselves reading their scripts using microphones that the Digital Storytelling Project grant at Kenyon College funded and mailed to students' homes. In the fifteenth week of the semester, I met with students individually to view their preliminary digital story videos. In these meetings, I provided feedback and answered questions about the process of compiling audio-visual material in WeVideo. Students at this phase asked about copyright permissions of images and music selections and for feedback on making transitions between images in the video clear and seamless in relation to their music selections and script recordings. In presentations during the final exam time allotted to the class, students screened their videos for their classmates. After each presentation two to three students asked questions and offered compliments to each other on their final digital storytelling projects. The final presentation of digital stories together as a class was a celebration of the hard work students did to complete their video projects and a reflection on the vast amount of material and digital media processing techniques that the students learned and employed.

\section{Outcomes and reflections}

Digital storytelling as a pedagogical practice continues the recently renewed attention to narrative learning, that, as Hakanurmi states, "combines narratives, learning, identity and agency" (2017, p.152). The Resulting projects from Anth391 told of varying topics and provided insight into perspectives and pressing matters in the lives of my students. One student explored racialized language use in the hip hop music industry in connection to contestations of artists' identities and race. Three students explored their gender identities and sexual orientations in relation to slurs and language used to label non-binary gender identities. One student presented a lighthearted story of learning the meaning of an English idiom, which she connected to the topic and concept of linguistic ideologies in a way that grounded the funny story to show not only the socializing power of idioms but 
also how children acquire language and cultural competence. Many students explored their experiences with language and socioeconomic status through reckonings with second generation immigrant cultural backgrounds, gentrification in their communities, identity changes seen through language when transitioning to life as college students, and the linguistic baggage all these processes entail. Each student produced a digital story that illustrated Lambert's (2017) and Hessler and Lambert's (2017) point that the making of digital stories, through seeing, assembling, and sharing the resulting digital stories, can serve as a means to learn and cultivate storytelling as part of a transformative learning process.

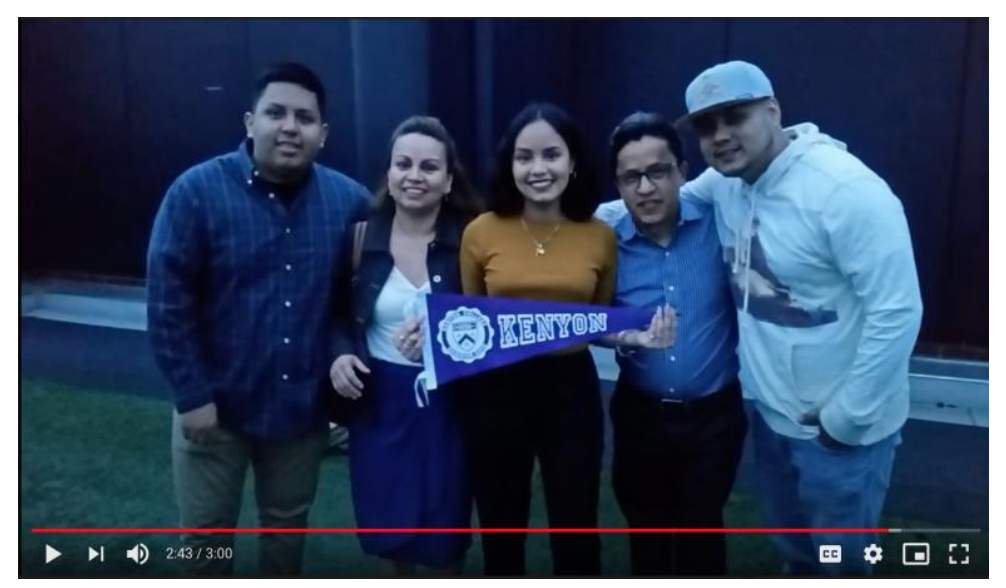

Image 2: A screenshot from a student s digital story about the transformation of her identity through language as a first-generation American and college student, used here with her permission.

The pedagogical power of digital storytelling was achieved through scaffolded assignments and a diverse range of activities, speakers, and materials through which students could observe and discuss the storytelling material of others, communicate their own stories in multiple ways, and forge connections with each other within a virtual classroom. A critical reading of linguistic, cultural anthropological, and linguistic anthropological academic material created a foundational lens through which students could bring their own questions to the fore about intimate engagements with language and identity formation through perspectives of power, standardization, and privilege (Hessler \& Lambert, 2017; Kaare, 2012; Myer \& Land, 2003). Two challenges emerged that I had not anticipated: firstly a couple of students were not comfortable sharing personal stories or photos featuring friends and relatives, and they consequently felt their scripts and videos were not as valuable as other students who shared intimate stories with ease. Additionally, a few students struggled with selecting a story about their identities they felt was 'impactful enough' to share with others. As a result, they took a great deal of time to decide on a subject, and given the lengthy project development process, it led to difficulties in finding material, such as photos and music, later on when time was short. When students were hesitant about sharing details about themselves or unable to choose topics that resonated early on, I suspect they did not connect with the course material as much as others as they progressed through the many scaffolded assignments leading to the final videos. In future iterations of this project, if students find it difficult to hone in on or tell a story about themselves, I would urge them to look to their surroundings and tell a compelling story capturing elements, topics, and characters from their local communities with permission from those members. Overall, my students welcomed the creative format as a way to share, process, and work through current events and experiences in their lives leading up to the class. Many examined assumptions about their identities, communities, and language use through critical perspectives using what they expressed to me was an accessible project format and software for digital storytelling.

After this first semester using digital storytelling as pedagogy, I would be enthusiastic to facilitate digital storytelling projects again, either in-person or in a virtual learning setting. The small seminar class size was also conducive to the intimacy the projects necessitated, but a sense of small-group intimacy and collaboration can be replicated in a larger class through a collection of stable groups of students who meet together periodically over the course of a semester. When implementing this project again, I would emphasize strongly at the beginning of the process that students need to have thought through what kinds of visual media they can prepare and feel comfortable sharing with the class as part of this project. As Lambert (2017) and Hakanurmi (2017) emphasize, the collaborative process of meaning-making in storytelling and digital storytelling pedagogies is important. The small seminar course provided a setting for collaborative experiences where students learned together and tested 
theories and ideas stemming from material and feedback on assignments, that deepened student understanding. In specific activities with peer collaboration, students worked with each other to foster connections between course material and their own lives, shifting individualized perspectives to collaborative and collective ones to help each other succeed together (Kaare, 2012). Story work has this integrative potential to expose previously hidden connections between concepts and elements under examination (Hessler \& Lambert, 2017; Meyer \& Land, 2003). Using storytelling as a pedagogical vehicle that drew on students' own languages and identities amid the current events unfolding in the United States, allowed students to engage with course materials to understand real world context beyond our remote classroom. During the covid-19 restrictions in the fall semester of 2020, ethnographic storytelling also allowed students to remotely create connections with each other without ever setting foot in the same physical classroom space.

Teaching throughout this time has left me in no doubt that utilizing digital storytelling as pedagogy, whether in online or face-to-face course delivery, has the potential to be a transformative, creative, and inclusive classroom practice. In my course I used it to deepens student understanding of identity formation experiences, but there is scope to apply it to enrich the teaching of many more anthropological subjects.

\section{References.}

Aguilera, E., Lopez, G., Frankel, K.K. \& Brooks, M.D. (2020). Centering First-Generation College Student's Lived Experiences Through Critical Digital Storytelling, Journal of Adolescent and Adult literacy, 63 (5), 583587.

Alexander, B. (2011). The new digital storytelling: Creating narratives with new media. Santa Barbara: Praeger.

Alexandra, D. (2008). Digital Storytelling as Transformative Practice: Critical Analysis and Creative Expression in the Representation of Migration in Ireland. Journal of Media Practice 9 (2), 101-12.

Benick, G. (2012). Digital storytelling and diasporic identities in higher education, Collected Essays on Learning and Teaching, v5, 147-152.

Benmayor, R. (2008). Digital storytelling as a signature pedagogy for the new humanities. Arts and Humanities in Higher Education, 7, 188-204. Doi: 10.1177/1474022208

Dunford, M., and Jenkins, T. (2017). Digital storytelling: form and content, Palgrave Macmillan, Basingstoke.

Hakanurmi, S. (2017). Learning to Work Through Narratives: Identity and Meaning-Making During Digital Storytelling. In Digital Storytelling in Higher Education: International Perspectives, edited by Grete Jamissen, Pip Hardy, Yngve Nordkvelle, and Heather Pleasants, 149-66. Digital Education and Learning. Cham: Springer International Publishing. https://doi.org/10.1007/978-3-319-51058-3 11.

Hessler, B., and Lambert, J. (2017). Threshold Concepts in Digital Storytelling: Naming What We Know About Storywork. Grete Jamissen, Pip Hardy, Yngve Nordkvelle, and Heather Pleasants (eds) Digital Storytelling in Higher Education: International Perspectives, (pp.19-35). Cham: Springer International Publishing. https://doi.org/10.1007/978-3-319-51058-3 3.

Jamissen, G., Hardy, P., Nordkvelle, Y. \& Pleasants, H. (2017). Digital Storytelling in Higher Education: International Perspectives, Palgrave Macmillan, Secaucus; New York.

Kaare, B. (2012). The Self and the Institution. Nordicom Review 33 (2), 17-26. https://doi.org/10.2478/nor-2013$\underline{0011 .}$

Kuyvenhoven, J. (2009). In the Presence of Each Other: A Pedagogy of Storytelling. University of Toronto Press.

Lambert, J. (2017). The Central Role of Practice in Digital Storytelling. Mark Dunford and Tricia Jenkins (eds) Digital Storytelling: Form and Content, (pp. 21-26). London: Palgrave Macmillan UK. https://doi.org/10.1057/978-1-137-59152-4_2.

Lambert, J. and Hessler, B. (2018). Digital Storytelling: Capturing Lives, Creating Community. Routledge \& CRC Press. 
Teaching Anthropology 2021, Vol. 10, No 3, pp. 90-96.

Meyer, J. and Land, R. (2003). Threshold Concepts and Troublesome Knowledge: Linkages to Ways of Thinking and Practising. Rust, C (Ed), Improving Student Learning: Ten Years On (pp. 412-424) OCSLD, Oxford.

Pink, Sarah. 2007. Doing visual ethnography: images, media, and representation in research. Sage Publications, London; Thousand Oaks, Calif.

Rolon-Dow, R. (2011). Race(ing) stories: Digital storytelling as a tool for critical race scholarship. Race, Ethnicity and Education, 14(2), 159-173.

Stewart, K.D. \& Ivala, E. (2017). Silence, voice, and other languages": Digital storytelling as a site for resistance and restoration in a South African higher education classroom, British Journal of Educational Technology, 48(5), 1164-1175.

Stewart, K. \& Gachago, D. (2016). Being human today: A digital storytelling pedagogy for transcontinental border crossing. British Journal of Educational Technology, 47(3), 528-542.

Nuñez-Janes, M., Thornburg, A., and Booker, A., (2017). Deep Stories: Practicing, Teaching, and Learning Anthropology with Digital Storytelling. Electronic resource. Berlin: De Gruyter

Tyner, K. (1998). Literacy in a digital world: Teaching and learning in the age of information. New York: Routledge.

\section{Acknowledgements}

I would like to thank the students of Anth 391 at Kenyon College over the fall semester in 2020 as well as the Kenyon College Center for Innovative Pedagogies for their support for a Digital Storytelling course. This course would not have been possible without funding from Kenyon College s Digital Storytelling initiative and mentorship from StoryCenter.

\section{Disclosure Statement}

The author(s) declared no potential conflicts of interest with respect to the research, authorship, and/or publication of this article. 